\title{
Food hygiene challenges in older people: intergenerational learning as a health asset
}

\author{
H. Wythe, C. Wilkinson, J. Orme, L. Meredith \& E. Weitkamp \\ University of the West of England, Bristol, UK
}

\begin{abstract}
Older people are more at risk of contracting foodborne infections; however the majority remain well despite the physical, social and cognitive challenges of older age. Future healthcare strategies targeting older people can be informed by exploring the food history and current context of their lives and what 'assets' they employ to successfully consume 'safe' food in the home. Phase I: Sociodemographic, health and asset related data collection through a researcher completed questionnaire i) at 4 Age-UK lunch clubs ii) at a North Hertfordshire District Council community centre lunch club and iii) via a 3UA webpage in Buckinghamshire and Hertfordshire. 50 respondents recruited via self-selection. Quantitative data were analyzed using SPSS. Phase II: 15 semi-structured interviews conducted via purposive sampling from the questionnaire cohort, and 3 interviews with sheltered housing staff in Buckinghamshire. Qualitative data analyzed using a Grounded Theory approach with NVivo software. Mean age: 79 years (SD 8.9) from 62-99 years.19 Male (38\%), 31 female (62\%). Visual Analogue Scale (VAS) $10 \mathrm{~cm}$ scale for reporting subjective health: mean $6.8 \mathrm{~cm}$. $80 \%$ lived independently alone, either in their own homes or in sheltered accommodation. Exploring the reported belief that 'food hygiene didn't exist' during the childhood years of this population and theoretical development of concepts surrounding whether adult food hygiene practices were hidden and nonverbalized as viewed by children, or unnecessarily in times of a simplified food chain between producer and consumer. Adapting to modern food products has required the acquirement of new food hygiene knowledge and skills, with evidence that this knowledge is now being passed from the younger generation to the elder along with food provision.
\end{abstract}

Keywords: older people, food hygiene, health, assets, learning, family. 


\section{Introduction}

Little is known about the how food hygiene skills and practices were learnt by the older generation when they were young, and how those practices have altered throughout the life-course. This paper summarises the preliminary results of a pilot study which aims to identify the food hygiene 'assets' employed by older people to help explain how they manage 'safe' food in the home despite the challenges of older age. As part of this research, the food history of older people was explored together with how food hygiene knowledge and skills have been learnt and the impact of that knowledge transfer on the development of current practices.

Caring for an increasing elderly population is a global concern. In the UK The Office of National Statistics report that there has been a fivefold increase in people aged over 65 between 1901 and 2003, from 1.8 million to 9.5 million [1]. Projected figures anticipate that the greatest rise will be seen in the over $85 \mathrm{~s}$ rising from $1.9 \%$ of the population in 2003 to $3.8 \%$ in 2013 [1]. The UK government estimates that the average cost of providing hospital and community health services for a person aged 85 years or more is around three times greater than for a person aged 65 to 74 years [2].

Foodborne illness has been identified as a particular threat to the health of the older population .Older people have been identified as being more 'at risk' of food borne infections within the bio-medical paradigm. An age related decline in immunity [3-5], co-morbidities and long term conditions [6, 7], declining cognitive function [8] and sensory acuity [9] make older people more susceptible to contracting severe symptoms of foodborne illness. In the UK, recent information from the Food Standards Agency (FSA) [10] provides evidence of a rise in the incidents of Listeriosis monocytogenes in the older population. Cases of Listeriosis bacteraemia have increased three fold from 3.3-4.7 per million in 1990-92 to 13.2 per million in 2007 for those aged 60 or above in England and Wales [11]. The highest proportion of deaths from Listeriosis occur amongst individuals aged 80 and above (44\% of those infected compared with $27 \%$ of those aged 50-59 age group) [10]. Similar rises have been seen in other European countries [12]. The full cost of foodborne illness extends beyond social and personal cost to the individual. It has been estimated by the FSA that the full economic cost of foodborne illness in the UK could be as high as 1.5 billion pounds [13]. Maintaining the health of this population is of a primary concern, not just to preserve governmental funds, but also due to the moral obligation to protect the most vulnerable in our society.

The Advisory Committee on the Microbiological Safety of Food (ACMSF) to the FSA were called to investigate potential hypotheses to explain this rise of foodborne illness in the UK within this population. Theories around increased surveillance systems and increased pathogenicity of the organism were discounted, and recommendations were made that further research should explore the social systems and the behaviour of individuals. Social norms and influence greatly affect beliefs and conformity of behaviour [14-16] and constitute, in part, to models of behaviour such as The Health Action 
Model [17]. Likewise communication theories such as Berlo's 'Source, Message, Channel, Receiver Effect-Model' [18] and the development of 'social marketing' $[19,20]$ all recognise that understanding the social setting of people's lives will allow for the development of targeted of messages. These messages, such as Health Promotion initiatives, would have greater efficacy in inducing behaviour change in the target recipients.

It is worth noting that the vast majority of this age-group remain unaffected by foodborne illnesses, despite these challenges of older age. The health assets model of health promotion has gained recognition in recent years [21]. Drawing on 'salutogenic' [22] principles, the assets model seeks to identify what protective resources, or 'assets' people have available to them to maintain health despite the challenges of daily life. Morgan and Ziglio [23] argue that this nonmedicalised holistic approach to health, if used in conjunction with the traditional 'deficit' biomedical model, could reduce health inequalities still seen in the UK [24]. Assets can be operational at the personal level in terms of knowledge and experience, but also at the level of groups, communities and social systems. It has been used to map the social assets of younger people and the incidence of depression, alcohol use, suicide risk and violence [25]. This is a positive approach within the interpretative paradigm that indicates a culture shift in thinking about health; that the 'glass is half full not half empty' [26]. If the salutogenic or health protecting aspects of older peoples' lives could be explored and identified, and the social context of their lives understood, then this could help develop future healthcare strategies such as targeted health promotion messages.

Assets are an unexplored aspect of food hygiene in the homes of older people. We identified a range of assets that allowed older people to consume 'safe' food in the home. Food hygiene knowledge transfer was identified as an asset employed by older people to enable them to eat 'safe' food. This paper will outline the results of how food hygiene knowledge was shared within the social system of the family and how that may influence the current food hygiene practices of a group of older people currently living in the UK.

\section{Methods}

Study methodology and all research material (information sheets, consent forms, questionnaires and indicative interview questions) were approved by the University Faculty Ethics Committee.

\subsection{Sites}

1. The regional office of a major UK charity (AgeUK) was approached to seek permission to attend 4 of their 'lunch-clubs' in the Milton Keynes area in Buckinghamshire. These are social events which are held once a week within council-run sheltered accommodation where residents and non-residents met to share a meal, cooked on the premises by AgeUK staff, and to play communal games such as 'Bingo'. 
2. One community centre run by North Hertfordshire District Council was visited in Hitchin, Hertfordshire where lunch-clubs were also held. Other groups also used the centre such as exercise and dance classes and a group that organised assisted shopping excursions to the local supermarket.

3. An advert was posted on the local 'University of the $3^{\text {rd }}$ Age' website forming a 'virtual' site.

\subsection{Recruitment}

The 5 lunch clubs and associated interest groups were visited by the researcher over a period of 3-6 months to get to know the visitors and to establish trust and a rapport. Over this time-period, the researcher mentioned the study and distributed information sheets when appropriate, or read information to the visitors if they had poor eyesight. People had as much time as they needed to think about whether they wished to take part in either or both phases of the study. Consent was recorded either manually on the consent form or orally, captured on a digital recorder for those who had poor eyesight or dexterity. 50 people consented to take part in the study and completed the questionnaire, 15 older people were then invited to take part in a semi-structured interview.

\subsection{Methodology}

The study employed a mixed methods approach with three data collection phases.

I. A researcher-completed questionnaire. This fulfilled numerous purposes:

- $\quad$ To establish the number and range of assets employed by the older person to help them eat fresh 'safe' food in the home.

- To provide basic information on subjective health and socioeconomic status of the recruited population.

- $\quad$ To inform later semi-structured interview (phase II) [27].

- As a one-to-one interaction to help establish rapport between the researcher and participant.

The questionnaire had internal validation checks, with multiple questions seeking to gain an overall picture of health (subjective health via the EQ-5D and the $10 \mathrm{~cm}$ Visual Analogue Scale, state benefits received and health service use) and economic status (benefits received, residential area linked to deprivation indices) and food assets employed (number of meals at centre, food delivered to the home).

Questionnaire data was then collated and interrogated using 'SPSS' software to determine both descriptive and inferential statistical data.

II. Certain participants who completed the questionnaire were then invited to take part in a semi-structured interview to fulfil purposive sampling requirements. Following an introduction surrounding confidentiality and 
'warm-up' questions surrounding the childhood home, discussion was focused on how food hygiene skills (as assets) were acquired in the past (personal communication, advertising, health promotion, schooling, experience), and how they may have changed in later life. Discussion followed on how family, community and service assets are used, and how these are organised to adapt to changing health needs. Towards the end of the interview, participants were given the opportunity to add further information and ask any questions they may have. Interviews lasted between 40 minutes and 1 hour. Participants were verbally thanked for their time and were later sent a card in the post to express the researcher's appreciation.

III. Semi-structured interviews were also undertaken with the managers of 3 sheltered accommodation sites following permission from Milton Keynes Council. The purpose of these interviews was to gain an insight into their thoughts and opinions on how older people manage food and the assets that they employ. These data would provide an over-arching view of the topic from an 'outsider' perspective who is familiar with a number and range of situations exemplified by the older people they help care for.

\subsubsection{Qualitative data analysis}

All interviews were digitally recorded and typed up verbatim on an on-going basis as interviews were completed. The transcripts were checked against the audio files for accuracy and completeness and to also allow familiarisation with the data. Transcripts were then uploaded into NVivo computer software, where they were re-read and gross line by line coding commenced to establish content related themes and subthemes. Subsequent transcripts were compared to these existing themes and coding frames, range and code titles were modified and rethought in a process consistent with the 'constant comparative' method of Grounded Theory [28]. Extensive memo writing accompanied the coding process to help establish key themes and to identify which participants should be approached for future interview.

Using both qualitative and quantitative data allows for crossvalidation/triangulation of results both within and between the questionnaire and interview cohorts [29, 30]. The credibility of the study findings was enhanced through the piloting of the research tools within each phase [31] allowing amendments to be made where necessary. Reflexive field notes were kept to maximise validity by limiting internal researcher bias during the data collection and analysis process.

\section{Results}

\subsection{Phase I}

50 people were recruited during the interview stage (Phase I) across the 6 sites. The table below summarises the main demographic, health and marital data of 
those who took part across the different sites collected during Phase I, and those chosen for interview for Phase II. 15 people from Phase I undertook an interview (8 women and 7 men). People with different marital status, health and age were invited to take part to fulfil the purposive sampling strategy of identifying those exposed to a range of food hygiene 'assets' during their life-course.

Table 1: $\quad$ Age, health and marital status of participants in Phases I and II of the study from all study sites.

\begin{tabular}{|c|c|c|c|c|c|c|c|c|}
\hline \multirow{4}{*}{ Site } & \multicolumn{4}{|c|}{ Phase I- Questionnaires } & \multirow{2}{*}{\multicolumn{4}{|c|}{$\begin{array}{c}\text { Phase II- Interviews } \\
\text { Marital status }\end{array}$}} \\
\hline & \multirow{2}{*}{\multicolumn{2}{|c|}{$\begin{array}{c}\text { Sex recruited } \\
\text { And Marital status }\end{array}$}} & \multirow{4}{*}{$\begin{array}{c}\text { Mean Age } \\
82 \\
\text { (SD 10.6) }\end{array}$} & \multirow{4}{*}{$\begin{array}{c}\begin{array}{c}\text { Mean VAS } \\
(\mathrm{cm})\end{array} \\
5.6(\mathrm{SD} 1.16)\end{array}$} & & & & \\
\hline & & & & & \multirow{3}{*}{$M^{\mathrm{M}}$} & \multirow{2}{*}{\multicolumn{3}{|c|}{$\begin{array}{l}\text { Mean } \\
\text { VAS }\end{array}$}} \\
\hline & \multicolumn{2}{|c|}{$\mathrm{M} \quad \mathrm{F}$} & & & & & & \\
\hline Site A & $\begin{array}{c}1 \mathrm{~W}, 1 \mathrm{D}, \\
1 \mathrm{M}\end{array}$ & $5 \mathrm{~W}$ & & & & & & \\
\hline Site B & $\begin{array}{l}\text { 1D, 3W, } \\
1 \mathrm{NM}\end{array}$ & $4 \mathrm{~W}$ & $\begin{array}{c}84 \\
(\mathrm{SD} 7.6)\end{array}$ & 6.9 (SD 1.38) & $2 \mathrm{~W}, 1 \mathrm{NM}$ & & 81 & 8.1 \\
\hline Site C & $2 \mathrm{~W}$ & $3 W$ & $\begin{array}{c}87 \\
\text { (SD 6.1) }\end{array}$ & 7.5 (SD 3.39) & & $2 \mathrm{~W}$ & 86 & 6 \\
\hline Site D & 2NM, 1D & $3 W$ & $\begin{array}{c}80 \\
\text { (SD 5.3) }\end{array}$ & 6.7 (SD 1.09) & 1D & $1 \mathrm{~W}$ & 81 & 6 \\
\hline Site E (NHDC) & $1 \mathrm{M}, 1 \mathrm{P}, 1 \mathrm{~W}$ & $\begin{array}{l}3 \mathrm{M}, 1 \mathrm{P} \\
5 \mathrm{~W}\end{array}$ & $\begin{array}{c}73 \\
\text { (SD 5.5) }\end{array}$ & 6.6 (SD 1.79) & & $1 \mathrm{P}$ & & \\
\hline $\begin{array}{l}\text { Site E: activity } \\
\text { groups }\end{array}$ & $1 \mathrm{~W}$ & 2NM, 1M & $\begin{array}{c}73 \\
\text { (SD 5.9) }\end{array}$ & 7.9 (SD 0.75) & $1 \mathrm{P}, 1 \mathrm{M}, 1 \mathrm{~W}$ & $1 \mathrm{~W}$ & 75 & 6.4 \\
\hline $\begin{array}{l}\text { Site E: shopping } \\
\text { group }\end{array}$ & $1 \mathrm{~W}$ & $3 \mathrm{~W}$ & $\begin{array}{c}86 \\
\text { (SD 5.2) }\end{array}$ & 6.6 (SD 2.3) & & $2 \mathrm{NM}$ & & \\
\hline $\begin{array}{l}\text { Site F:3UA } \\
\text { 'virtual site' }\end{array}$ & $1 \mathrm{M}$ & 1D & $\begin{array}{c}66 \\
\text { (SD 3.6) }\end{array}$ & 8.6 (SD 1.25) & & & & \\
\hline ALL & 19 & 31 & $\begin{array}{c}79 \\
\text { (SD 8.9) }\end{array}$ & 6.8 (SD 1.84) & 7 & 8 & 81 & 6.6 \\
\hline
\end{tabular}

$\mathrm{M}=$ Married; $\mathrm{D}=$ Divorced; $\mathrm{W}=$ Widowed; $\mathrm{P}$ = Have non-cohabiting partner; $\mathrm{NM}=$ Never married; RM= Re-married.

\subsection{Phase II}

A number of key content-related themes developed during the course of qualitative data analysis, this paper will highlight two of these themes:

1. The recalled beliefs and related experiences of observing and partaking in food hygiene practices during the childhood home of older people.

2. The food hygiene practices of older people are being influenced by the younger generation (family members and health carers), alongside the provision of food as an aspect of 'care'.

\subsubsection{Theme I - 'food hygiene didn't exist in those days'}

12 out of the 15 interviewees could not recall any food hygiene practices being undertaken, or the term 'hygiene' being used in the home with regards to food when they were children 'we had a cupboard in the living room if you like and the bread and butter was kept in there, but food hygiene didn't exist in those days' (Arthur: aged 85 years). Different aspects of current food hygiene practice will be discussed and compared with the past experiences of those interviewed.

Past food preparation practices were described as being 'general' or 'very informal' and even 'automatic', whilst others referred to it being 'the kind of 
common sense thing', suggesting that it was not consciously thought about and that it was highly habitual. Food storage facilities were very limited in the childhood homes of older people, and therefore without fridges or freezers there was little scope to keep food in currently recommended conditions: '[differing food-stuffs] it was all on one shelf so there was no thing of keeping cooked meat separate from fresh meat because it just didn't happen, certainly not while I was young anyway' (Beth: aged 64 years).

When hygiene was mentioned, it was in relation to hand washing and personal hygiene. Hand washing took place when they were perceived as being visibly dirty: 'I don't ever remember, apart from maybe washing your hands because they were sticky or had blood on, you know what I mean from meat or whatever' (Beth: aged 64 years). Hand washing was generally instigated by the parent upon the child, forming a practice that had particular salience to the interviewee. Other visible practices witnessed by the child were general cleaning of the kitchen and the house but this was not necessarily associated with hygienic practices even when it took place in the kitchen.

All interviewees were aware that food hygiene practices had developed in time over the course of their lives, that 'we never did all this date business like they do now' (Rosie: aged 80 years). There was the general acceptance that this change has come about through the development of supermarkets, which they use because of the perceived value for money that they can offer. The benefit of the convenience and economy of supermarket food purchasing has been offset with the acceptance of now having little information on the food available i.e. source and age. George's statement below that he 'knew' about food in the past 'unlike today', even though use-by date are provided on modern food, this is not the same as 'knowing' how long it could be kept for:

\section{I: 'Do you remember learning about food hygiene at all?}

$R$ : No, no I knew that if things weren't used very much they would go out and finish them before and up to the date, but I knew unlike today that there was only a certain period of time when you could store food to eat irrespective of what the food was' (George: aged 79 years).

Engendered roles were very prevalent in the childhood houses of older people, with mothers being described as 'the queen of the kitchen' (Jean: aged 88 years), that the kitchen was the mother's domain and looking after the house was her sole role: 'she spent half of her time in the kitchen, poor soul, either cooking or cleaning it, you know doing stuff.' (Jean: aged 88 years). As a result it was accepted by some that they were not privy to all of the practices that took place in the kitchen, because they were at school or otherwise occupied whilst those practices were being undertaken:

'I didn't do that, I didn't lay the table, I got to admit it wasn't one of the things I did, table laying, mum did all that. So I don't think I knew where a jam jar or a pat of butter was, it just appeared on the table in front of me and I would sit down and eat it and then get up and leave.' (Frank: aged 74 years). 
Frank repeats the assertion several times that he wasn't involved, that it wasn't his 'role' it was his mother's and there seems to be a realisation that he knew little about where food was stored and how it was cooked when he was a boy. Other men reported only having an involvement with cooking as boys when it was associated with a male pastime, such as collecting 'badges' as members of a scout brigade. Collecting badges had a strong element of masculine competition in that collecting as many badges as possible provided them with an elevated status amongst the scout troop. This gave them the impetus and social 'permission' to learn to how to cook from their mothers, however food hygiene was still not recognised as taking place beyond the general hygiene practice of hand washing and occasionally kitchen cleaning.

\subsubsection{Theme 2 - Intergenerational transfer of food hygiene skills and practices}

Family and carers frequently provided pre-prepared food for interviewees for them to eat at a later mealtime. Alongside this food provision role, advice was given on how pre-prepared food should be cooked:

I: So how do you manage the microwave with your poor eyesight?

$R$ : Oh Ed tells me what to do just turn it a little bit, give it so long all according what you are having and I manage all right you know, yeah it's only the soup really that I put in there, you know to heat up.

I: So you put his meals in there don't you, so he tells you how long to cook it for? R: Yeah...

I: ...and can you see all right to...?

R: No I just judge, I just judge' (Mary: aged 93 years)

The quote above does indicate that even though food is being provided, reheating pre-prepared food can still prove to be difficult resulting in some 'guesswork' for the older person in the final stages of food preparation. She 'manages' by 'judging'; she cannot be sure that she has prepared it correctly; she just knows that she has to 'turn it a little bit'. There was also evidence that some interviewees thought that not so much care was needed when re-heating prepared food than if it was cooked from scratch: 'Because my daughter has already cooked it its only like warming it up in the microwave.' (Rosie: aged 80 years). These quotes indicate that food provision takes priority as a basic physical need, whereas safety is secondary or not necessarily considered. However, when food hygiene practices are performed on behalf of the older person by younger family members or carers these were definitive and irrevocable. Most notably younger people visiting the homes of the elderly outside meal times undertook the process of removing out-of-date food from their fridges, effectively taking away the option of it being eaten:

R: 'Well funnily enough Jim usually does that, he says I say 'oh no its perfectly fine I have only had it three weeks' sort of thing he says 'mother' and he goes and he says 'that's out, that's out, that's past its sell buy that's out' so either Jim 
or Shirley come and very tactfully and kindly say look that's got mould on it what more do you want? (laughs).' (Jean: aged 88 years)

The removal of their food from fridges by family or carers was not something they felt comfortable with, with expressed feelings such as they had given in to current ideas or failed to make the best use of the food they had available: 'I have got carers they look at all the dates its only got to be one day out of date and in the bin it goes, oh dear.' (Rosie: aged 80 years). This is at odds with memories of austerity when food was an expensive commodity: 'I've seen people starve and I know what it's like, so I don't waste food.' (Henry: aged 90 years).

\section{Discussion}

The increasing global population has led to the large scale production of food, particularly to meet the needs of the affluent populations of Western Europe and North America. These changes in food production have occurred in a relatively short period of time, within the lifetime of older people living in the UK. This study has identified the concept that food hygiene was perceived not to 'exist' in the childhood lives of older people recruited into this study and we consider this impact on current practices. We have touched upon four aspects of current food hygiene practice that were perceived to be absent or have altered considerably during the life course of these older people 1) food storage conditions 2) 'knowing' the age of food 3) hand washing and cleaning and the concept that 4) food hygiene practices were 'hidden' and were largely unobserved. These four aspects warrant further consideration here.

The increased domestic use of fridges and freezers in the 1950s and 60s in the UK allowed for food storage to be extended beyond what was possible previously. The rise in fridge usage was dramatic; in 1956 just 8\% of householders in the UK owned a fridge, rising considerably to 23\% in 1961 and just over ten years later in 1972, 99\% of households owned a fridge [32, 33]. Although food preservation techniques such as pickling, canning and salting of foods had been practised for centuries, fridges provided a new dimension to preserving food by 'controlling nature' [34] by creating ice in the kitchen environment rather than purchasing it from delivery services. The fridge allowed food preservation to be extended to the entire family food stock, not to individual food-stuffs that may lend themselves to canning or pickling. Concurrent development of cooled food distribution and the later development of chemical preservatives meant that the 'life' of food stuffs was being extended to the maximum by food distributors and retailers for the benefit of all. Alongside the increasing use of cars, the weekly food shop at a supermarket first became possible and then became the norm [35], contributing in part to considerable social change.

Before the widespread use of fridges and during the childhood of the study participants living in towns and villages in the 1930s and 40s; meat, dairy and vegetables were purchased from local shops which were supplied by local farms. Vegetables were frequently grown at home to supplement war and post-war 
rationing, and those who were fortunate to live in the country had the opportunity to eat meat such as rabbit or fish obtained directly from the land. As such the age of produce was 'known'. Food could not be old as there was no way to preserve it, either chemically or by cooling it. Following the 'farm to fork' paradigm, this 'journey' was short and understood by those who consumed the food. If the age of food was 'known' then consumers may have felt empowered to make decisions on when food should be consumed, they were allowed to use their 'common sense'. Therefore if older adults do not recall food hygiene practices taking place in the home when they were young this may be due to the simple and short journey the food had made into the home and onto the table, negating the need for food hygiene practice as we understand it today. Consumers who were used to making informed decisions on food consumption in the past are now second guessing and intellectualising food distributors' motives and profits to maximise personal economy (paper in preparation). As such current 'food hygiene' practices encompass new ideas and new ways of 'knowing' how long food can be kept which are as new a 'product' of modern food as the food products themselves.

A further consideration is that microbiology was a relatively new scientific field during the interviewees' childhoods. 'Food poisoning' was not recognised terminology until the 1880s and it took until 1939 for it to become a notifiable condition to report to governmental offices at a time when public health laboratories were still scarce in the UK [36]. During the inter-war years the 'sanitary conscience' [37] of the public had been awakened except in relation to food hygiene where adequate hygiene measures were viewed as lacking [38], and the importance of hand washing was dismissed as a 'sanitary superstition' [39]. Toilet paper was seldom used and when it was, it was of such poor quality that it rarely protected the hands from soiling [40]. Hand washing facilities were also scarce and the cost of their inclusion in new building developments were deemed as an unnecessary expense, and where they were provided they were seldom used [41]. These scientific discoveries and recommendations regarding hand washing by the scientific community would have only been coming to the fore during the study participants' parental generation. It is likely therefore that hand washing as part of food hygiene practice was an unknown concept or possibly perceived as a 'new' and unnecessary practice for those who did prepare and cook food during the childhood homes of the older people in this study.

An alternative viewpoint may be seen from the perspective of food hygiene practices not being apparent because they weren't observed by the interviewees. Food hygiene practices are undertaken by those who store, prepare and cook food and as a result these practices are 'hidden' to others. Engendered roles were prevalent when older people were young and mothers generally had the 'default' role of cooking [42] and therefore were the guardians of food hygiene knowledge and practice along with cooking skills [43]. Consequently young children may not have been aware of food hygiene practices taking place in the parental home because they were not involved in food preparation. In addition, if any food hygiene practices were performed then these may have been non-verbalised and tacit, secondary to more overt cooking practices and learning. 
Those who provide food for an elderly relative or client today, so that they can retain their independence, can be viewed as expressing familial or professional care. As we have discussed above, food hygiene maybe viewed as a secondary concern compared to food provision itself when the considered older person may have long-established values regarding food waste or misconceptions regarding adequate re-heating methods. Sensory and cognitive challenges may also limit the ability of the older person to practise 'safe' food hygiene practices. Younger members of the family or carers who dispose of out of date items from an older person's kitchen are protecting them from harm by removing food hazards, and as such also demonstrate an equally valid expression of care as those who provide food. Older people may struggle to overcome a lifetime's experience of austerity and food scarcity by willingly throwing food away, but younger relatives or carers who undertake these food hygiene practices on their behalf are a valuable asset in helping protect them from food borne illness.

\section{Conclusion}

Older people may have had to learn food hygiene independently throughout the course of their lives. If the subjective view prevails that 'food hygiene didn't exist' when they were young, then the acceptance of its value beyond 'common sense' values and beliefs may be difficult to change for some. Whatever the likely cause, evidence suggests that the older people taking part in this study had limited exposure to food hygiene practices when they were young. There is additional evidence suggesting that if food hygiene practices were undertaken, they may have been tacit or of secondary importance in relation to cooking skills or unshared in the home environment due to delineated roles. Therefore food hygiene practices may have to be learnt and continually updated throughout the life course, requiring considerable awareness and understanding of modern food production methods, distribution and cooking technology. Evidence from this study also suggests that those who are at the greatest health 'need' and who have food provided or prepared for them by family and carers have the greatest help or health 'asset' in individuals who may undertake food hygiene practices for them alongside food provision. Therefore those older people who contract a foodborne illness may be demonstrating a symptomatic response to a wider social and health care need.

By appreciating the context of older people's lives and their food background history we believe that novel food hygiene health promotion strategies could be devised to communicate this considerable health risk to this population or to those who care for them. Particular attention should be focused on those who have had persistent limited opportunity to observe or practise food hygiene practices throughout their lives and those who are struggling to care for themselves preceding more intense social and health care intervention. 


\section{References}

[1] Tomassini, C., The demographic characteristics of the oldest old in the United Kingdom, Office for National Statistics. Population Trends, 120, pp. 15-22, 2005.

[2] Parliament UK, http://www.parliament.uk/business/publications/research/ key-issues-for-the-new-parliament/value-for-money-in-public-services/theageing-population/

[3] Chandra, R. K., Nutrition and the immune system from birth to old age. European Journal of Clinical Nutrition, 56(Suppl 3), pp. S73-S76, 2002.

[4] Chandra, R. K., Imbach, A., Moore, C., Skelton, D., and Woolcott, D., Nutrition of the Elderly. Canadian Medical Association Journal, 145(11), pp. 1475-1487, 1991.

[5] Meyers, B. R., Infectious diseases in the elderly, an overview. Geriatrics, 44, pp. 4-6, 1989.

[6] Wilson, T., Buck, D., and Ham, C., Rising to the challenge: will the NHS support people with long term conditions? British Medical Journal, 330(7492), pp. 657-661, 2005.

[7] Department of Health http://www.natpact.info/uploads/Chronic\%20 Care\%20Compendium.pdf

[8] Knapp, M., Prince, M., Albanese, E., Banerjee, S., Dhanasiri, S., Fernandez, J. L., et al., Dementia UK: A report to the Alzheimer's Society on the prevalence and economic cost of dementia in the UK produced by King's College London and London School of Economics. Alzheimer's Society: London, 2007.

[9] Schiffman, S. S., Taste and smell losses in normal aging and disease. JAMA, 278(16), pp. 1357-1362, 1997.

[10] Advisory Committee on the Microbial Safety of Food. Ad Hoc Group on Vulnerable Groups. Increased incidence of Listeriosis in the UK. Food Standards Agency: London, 2009.

[11] Gillespie, I. A., McLauchlin, J., Grant, K. A., Little, C. L., Mithani, E., Penman, C., et al., Changing pattern of human listeriosis, England and Wales, 2001- 2004. Emerging Infectious diseases, 12(9), pp. 1361-1366, 2006.

[12] Goulet, V., Hedberg, C., Le Monnier, A., and Valk, H., Increasing incidence of listeriosis in France and other European countries. Emerging Infectious Diseases, 14(5), pp. 734-740, 2008.

[13] Annual Report of the Chief Scientist 2011/12. Safer food for the nation, Food Standards Agency, 2012. http://www.food.gov.uk/multimedia/pdfs/ publication/csar1112.pdf

[14] Sherif, M., The psychology of social norms. Harper and Row; New York, 1935.

[15] Ash, S. E., Effects of group pressure upon modification and distortion of judgements. Groups, leadership and men, ed. H. Guetskow, Carnegie Press; Pittsburg PA, 1951. 
[16] Ash, S. E., Studies of independence and conformity: a minority of one against unanimous majority. Psychological Monographs, 70 (Whole 461), 1956.

[17] Tones, K., Devising strategies for preventing drug misuse; the role of the Health Action Model. Health Education Research, 2, pp. 305-317, 1987.

[18] Berlo, D. K., The process of communication. Holt, Rinehart and Winston: New York, 1960.

[19] Weibe, G., Merchandising commodities and citizenship on television. Public Opinion Quarterly, 15, pp. 679-691, 1952.

[20] Kotler, P., and Zaltman, G., Social marketing and public health intervention. Journal of Marketing, 45(2), pp. 3-12, 1971.

[21] Lindstrom, B., and Eriksson, M., Contextualizing salutogenesis and Antonovsky in public health development. Health Promot. Int., 21(3), pp. 238-244, 2006.

[22] Antonovsky, A., Health, stress and coping. Jossy-Bass: San Francisco, 1979.

[23] Morgan, A., and Ziglio, E., Revitalising the evidence base for public health: an assets model. Health Promotion \& Education, 14(sup 2), pp. 17-22, 2007.

[24] Duggan, M., Social exclusion, discrimination and the promotion of health. Promoting Health, Politics and Practice, eds L. Adams, M. Amos and J. Munro, Sage: London, 2002.

[25] Leffert, N., Benson, P. L., Scales, P. C., Sharma, A. R., Drake, D. R., and Blyth, D. A., Developmental assets: Measurement and prediction of risk behaviors among adolescents. Applied Developmental Science, 2(4), pp. 209-230, 1998.

[26] Improvements and Developments Agency (IDeA) Healthy Communities Team, A Glass Half Full: how an assets approach can improve community health and wellbeing. Local Government Association, p. 7, 2010.

[27] Robson, C., Real World Research (2nd Edition). Blackwell Publishing: Oxford, 2002.

[28] Glaser, B., and Strauss, A., The Discovery of Grounded Theory. Strategies for Qualitative Research. Aldine Publishing Company: New York, 1967.

[29] Denzin, N. K., The research act (3rd Edition ed.). Prentice Hall: Englewood Cliffs, NJ, 1989.

[30] Flick, U., Triangulation revisited: Strategy of validation or alternative? Journal for the Theory of Social Behaviour, 22, pp. 175-198, 1992.

[31] Denzin, N. K., and Lincoln, Y. S., Strategies of Qualitative Inquiry. Sage: London, 1998.

[32] Food freezer and refrigerator council (FFRC), Fridge and freezer fact card. FFRC: London, 1972.

[33] Office for National Statistics, Living in Britain; results from the 2001 General Household Survey. The Stationery Office: London, 2002.

[34] Grahame, P., Objects, texts and practices: the refrigerator in consumer discourses between the wars, The Socialness of Things: essays on the socio- 
semiotics of object, ed S.H. Riggins, Mouton de Gruyter: New York, pp. 285-307, 1994.

[35] Food Standards Agency, Consumer attitudes to food standards wave 4. England Regional Support, Food Standards Agency and COI Communications: London, 2004. http:/www.food.gov.uk/multimedia/ pdfs/cas2003er.pdf

[36] Hardy, A., Food, hygiene and the laboratory. A short history of food poisoning in Britain circa 1850-1950. Social History of Medicine 12(2), pp. 293-311, 1999.

[37] Porter, C., The public and food hygiene. Journal of the Sanitary Institute XLVI (427), 1924-25.

[38] McClure, W. St. C., The importance of cleanliness in the preparation and distribution of food. Journal of the Sanitary Institute, XLIV (315), 1923-4.

[39] Sanitary Superstition, The Lancet i (398), 1910.

[40] Whitbread, F. G, Feacal Organism Carriers. Journal of State Medicine, 34(734), 1926.

[41] Ministry for Health, Precautions against the alimentary infections. Ministry of Health Annual Report, 2198 (29), 1940.

[42] Sullivan, O., Time waits for no (wo) man: An investigation of the gendered experience of domestic time. Sociology, 31(2), pp. 221-239, 1997.

[43] Caraher, M., Dixon, P., Lang, T., and Carr-Hill, R., The state of cooking in England: the relationship of cooking skills to food choice. British Food Journal, 101(8), pp. 590-609, 1999. 